THURSDAY, MAY 23, 1872

\section{THE OXFORD SCHEME OF NATURAL SCIENCE*}

A LL true lovers of English science, we might say all A discerning lovers of their country, must have watched with anxious interest the efforts which in these latter times a few able and energetic men at each of our ancient universities have been making to strengthen and widen the study of Natural Science in those so-called seats of learning; and must have admired the zeal and wisdom with which they have fought against the stubborn resistance of the powers that be. To all such the recently-issued prozramme of the Board of Natural Science Studies at Oxford will have particular interest; for upon the wisdom of the regulations introduced by that Board will depend in great measure the future of Natural Science at Oxford.

In calling attention to this programme we shall so far rely on our well-known admiration of the talents and energy of the members of the Board as to take leave to say nothing of its good points. These will be read and known of all men who love science; and the results of the scheme, as far as its good features are concerned, will be the reward of its framers, whether, as we hope, they succeed in establishing Natural Science at Oxford in its proper dignity and power, or whether, as we fear, they eventually succumb to all those many influences which seem slowly but surely to be pressing the life out of both Oxford and Canbridge.

We think we shall be best furthering the interests of Science if we content ourselves with pointing out the blots of the scheme, blots which stand out in the stronger relief the more one dwells on what ought to be its immediate results, viz., the destruction of mere cram-work and the encouragement of the spirit of original research.

We learn that the student who wishes to take honours in Natural Science, must undergo a previous examination in the elements of Mechanics, Physics, and Chemistry. We have no remark to make on this, except to suggest that if the elements of Biology had been added, matters would have been vastly simplified, and much of the confusion to which we shall have presently to refer entirely done away with.

Having passed this previous examination, the student may elect to be examined in either Physics, Chemistry, or Biology, with or without certain special subjects, such as Geology, Zoology, or Botany.

Touching the examination in Physics we will simply express our regret that there is no definite statement that the examination in this branch will be partly of a practical kind. This is of course intended, but it is not specially stated. If the distinguished Oxford Professor of Experimental Physics knew what hard work his friends had to persuade the world that his superb laboratory is a real honest workshop, and not a gorgeous palace and magnificent show-room, he would have had the instructions touching the practical part of the examination in Physics printed in capitals or italics rather than omitted altogether.

* Notice of the Board of Studies for the Natural Science School of the University of Oxford, 1872 .

VOL. VI.
With regard to the Chemistry we will only remark that the restriction of the practical part of the examination to the old-fashioned inorganic analysis seems to us to mark an opportunity lost. Is the detection and estimation of a base and an acid for ever to remain the be-all and end-all of practical chemistry? We trust not. A change in this respect must soon take place in our examining bodies, and Oxford might have led the way.

It is to the biological part of the scheme that we desire more particularly to call the attention of our readers. The student who wishes to go out in Biology may take the general subject of Biology either alone or together with certain restricted special subjects, such as Comparative Osteology, Ethnology, \&c., or together with either of the larger special subjects, Zoology, Botany, and Geology. The general subject of Biology comprises General and Comparative Anatomy and Histology, both animal and vegetable, Human and Comparative Physiology, with Physiological Chemistry, and "the general philosophy of the subject." Our readers will naturally wonder what is meant by this last heading. They probably have been accustomed to consider that science is philosophy, and that the philosophy, for example, of comparative anatomy, grows out of the facts organically, is borne by the subject as plants bear flowers and fruits, and cannot be pinned on, like an artificial blossom on a garland, either in an examination or elsewhere. The mystery disappears when we turn to the list of books recommended (about which we shall have a word to say), where we find under the head of Genera Philosophy Agassiz" "Classification" and Whewell's "Inductive Sciences." Evidently the Board desires to try the students as the saints of old were tried in order to be made perfect ; they tempt them with courses of evil reading to see whether the truth be in them or no. But to return : the scheme, as it stands at present, does very well for a man who goes in for the general subject of Biology on the strength of his acquaintance with the contents of the Oxford Museum, and his knowledge of that Physiology falsely so called which is built up on a comparison of the organs of one animal with those of another. The practical examination in dissections and histological preparations will most likely fairly test his proficiency in these matters, and if he takes up one of the minor special subjects he will probably have a good but limited idea of one particular series of facts, e.g., the various forms of stomach presented by the animal kingdom. We doubt very much if the examination and preparatory course of study will have helped to make him a fruitful man of science, working in and for ideas. Probably the reverse.

But how much better off is he than the poor botanist who goes to seek at Oxford the means and help to make a working man of science of himself. He must first go through the general examination in Biology, must cram up text-books on Human Physiology, must read up all the futilities of the modern animal histologists, and dabble in the speculations of physiological chemists, to say nothing of his knowledge of the exoskeleton of the Arthropoda and other bits of special animal morphology, before he can turn to his heart's desire, the classification of Phanerogams. And he will cram; that will be the inevitable result.*

* The prolixity of some mambers of the Board seems to have driven the framer of the section of Botany into the opposite extreme. We cannot think it intended that the examination in Botany should be so feeble as the programme seems to intimate. 
Hardly better off is the physiologist, properly so called. What he needs as general education is a thorough knowledge of physics and chemistry, with a general acquaintance with the fundamental laws and simpler facts of animal morphology. Instead of that, this scheme takes him away from physics and chemistry, and tries to smother him with the specialities of morphology, to which he most probably has a decided natural repugnance.

Worst off of all is the geologist, who has to go in for all three general subjects before he can make his special knowledge weigh with examiners, and who therefore will be induced to keep on cramming heterogeneous knowledge up to the last moment; forasmuch as the statutes tell him that his place will depend "on the joint result of his examination in all his subjects."

In our humble opinion it would have been far better to have made the previous examination to include the elements of Biology, and at the same time rather more searching as a whole. Every science scholar would then have known something of everything essential in Natural Science. Freed by this examination, he might have turned at once to that something of winich he ought to know everything - to Geology, to Botany, to Animal Morphology, to Physiology, to Chemistry, to Physics. He would thus have, on the one hand, a sound foundation, with an insight into "the general philosophy," properly so called, of all science, and by early training in a special branch would have had his face set towards original work. We have no space left to criticise the various items of the special directions under Biology, Geology, \&c.; but we cannot refrain from uttering our protest against the pernicious habit, carried to an excess in this programme, of recommending particular books for study. This always means "particular books for examination," and is the most potent nurse of cram. Nor is the evil mended much by making the list of books large and long; for rather another evil is then introduced, viz., that of giving authoritative sanction to bad books. We venture to assert that no man of science can look through the list of books appended in this programme to his own particular line without being compelled to admit that some of the books recommended are essentially bad. We have spoken freely because the matter is one we have at heart. We must confess that the scheme at Oxford, as it stands at present, is inferior to that at Cambridge (excepting always that fearful system of order of merit, which hangs like a millstone round all Cambridge studies), and decidedly inferior to what the scientific examinations of the University of London will be when some necessary changes have been made in its $\mathrm{B}$.Sc.

\section{MÄDLER'S HISTORY OF ASTRONOMY}

Geschichte des Himmelskunde, nach ihrem gesammten Umfange, von Dr. J. H. von Mädler, Emeritirtem Professor und Director der Sternwarte, Dorpat. I Band, i. ii. iii. Lieferungen. (Braunschweig, 1872. London : Williams and Norgate.)

A PERIOD when the love of astronomical studyA long confined to a few select votaries, and dormant in general estimation-has attained an unprecedented and unlooked-for diffusion, is well suited for the appear. ance of such a historical view of the subject as may not only form a book of reference and comparison for the more advanced cultivator of the science, but may commend itself to the less instructed student, as well by the accuracy of its statements as by the perspicuity of its views and the simplicity of its expression. The work of which the earlier portion is now lying before us, seems, as far as can be foreseen, well calculated to answer this end, and Germany may be congratulated upon the com. mencement, at least, of what, ere long, ought to be made popularly accessible among ourselves. We possess, indeed, already, in the "History of Physical Astronomy," by Prof. Grant, a work of the highest pretension as to accuracy and intelligence; but the subject is there regarded from a different point of view, and treated in a different manner, and there is abundant room for each of them.

For those who venerate the Observatory of Dorpat, from the high position which it took and maintained under the elder Struve, as well as for those who love to contemplate and examine in detail the wonderful features of our satellite, this work will possess a double interest, both as originating within the walls of that honoured building, and as proceeding from the pen of the leading selenographer of his own time. It is only to be hoped that the advancing years of the venerable author may not interrupt the progress of what has been so auspiciously begun. At present it has been carried only as far as the establishment of Tycho de Brahe, as it seems to be the inaccurate custom of the Germans to call that great man, in his island of Hween, where "lived the Prince of Astronomy in external fitness, with princely aspect and splendour." But before the science had attained this due recognition as worthy of royal patronage and aristocratic cultivation, it is needless to say that it had to pass through long periods of darkness and discouragement and difficulty, when its progress was retarded by superstitious bigotry, chilled by heedless indifference, or entangled by the substitution of imaginary hypotheses for the patient labour of protracted investigation; and in tracing through all these impediments its gradual and interrupted advance, the learned author has shown not only a full command of the subject, but great fairness and discrimination in its treatment; and if it might be hinted that the style is sometimes encumbered by a repetition of unvaried metaphors, yet it is always perspicuous and pleasing. The only point as to which positive censure would not be invidious is no fault of the author, but of the corrector of the press, who must be held answerable for some offensive errata in the Greek and Latin citations. For errors in English and Welsh, through which Bradley's benefices of Bridstow, in Herefordshire, and Llanddewi-velvre, in Pembrokeshire, appear as "Bradstone" and "Welfric," some intermediate authority must be responsible; but we may fear that our own rendering of German names is not invariably more accurate. In order not to interrupt the current of the history, much of the biographical matter appears in the form of notes at the foot of the page, frequently of especial interest; we feel, however, the want of occasional references. The intensity of the author's annoyance at the monkish system may possibly lead some readers to an occasional smile; but with the Papacy as a whole no religious difference has prevented him from dealing with the candour and justice of a true historian. Of Pliny's merits he has formed a very unfavourable judg 